DOI: $10.14526 / 2070-4798-2020-15-1-67-75$

\title{
The effectiveness of physical culture elective courses realization using Nordic walking in terms of higher education
}

\author{
Svetlana V. Nageykina* \\ State University of Land use Planning and Control \\ Moscow, Russia \\ ORCID: oooo-ooo1-7305-9546, sveti-20oo@yandex.ru*
}

\begin{abstract}
In modern society the research works are constantly held using innovative approaches to physical activity organization among different groups of population. It is especially popular among students. Modern educational establishments are characterized by constant increase of students' intellectual activity. The amount of mental loads, tasks, projects increases. In this case students' physical activity decrease has negative influence on their organism. Hypodinamia is a chronic process. It is characterized by gradual decrease of muscles tonus, first of all the disorders in the work of cardiorespiratory system. A person's neuromuscular and locomotor apparatus are damaged. The aim of the research is to study the influence of systematic Nordic walking lessons on students' health indices. Research methods. In order to estimate the level of students physical health we held the test of functional indices, such as heart rate (HR), lung capacity (LC), physical working capacity, Skibinskaya index, birth-death ratio, health level according to Apanasenko. 44 students of the $2^{\text {nd }}$ course of the State University of Land use Planning and Control took part in the research work. After defining the initial level of the indices we formed one control and one experimental group. In the control group lessons were held taking into account the demands of the physical culture and sport elective course working program. In the experimental group we used the methodology, directed toward Nordic walking use in three directions: therapeutic, health improving and sports. Results. In order to estimate the initial level students' physical health in the experimental and control groups we used the diagnostics, offered by G.L. Apanasenko (2000). 35\% of students have a low level of physical health (LPH), 15\%- below the average, $45 \%$ the average level, $10 \%$ - above the average and 5\%- a high level of physical health. A low level of LPH among the students of the $2^{\text {nd }}$ course is mostly connected with motor activity decrease, especially during exams. In the EG after the methodology realization there was the amount of students increase, who have the average, above the average and high level of physical health. The safe level of students' health is the average and above the average level, where there are no adaptation disorders. Adaptive potential of students from CG and EG was defined with the help of functional indices study with transfer into points. Adaptive potential of students as the index of cardiovascular system functional abilities characterizes the range between health and disease. Before and after the experiment there were no cases of adaptation violation zones in CG and EG. The cases of students with unsatisfactory zones of cardiovascular system adaptation in CG and EG we connect with the fact that students didn't have aerobic loads of health-improving and training character for a long time period. After the experimental methodology realization we received the results. They characterize not only students' physical health level improvement, but also improvement of cardiovascular system adaptive potential to physical loads of aerobic orientation. Conclusion. Functional state indices study among the $2^{\text {nd }}$ course students revealed, that their physical health is at a low, below the average and the average level. Taking into consideration the studied indices we realized Nordic walking during physical culture lessons in three directions: therapeutic, health improving and sports. They differed in volume and intensity of physical loads. The volume of physical load was corrected taking into account an individual level of students' physical health according to the studied indices. In general the methodology realization demands the differentiated approach use to lessons organization, taking into account morphofunctional indices.
\end{abstract}

Keywords: elective course, methodology, Nordic walking, students, aerobic potential, physical health.

For citation: Svetlana V. Nageykina. The effectiveness of physical culture elective courses realization using Nordic walking in terms of higher education. Russian Journal of Physical Education and Sport. 2020; 15(1): 57-63. DOI: 10.14526/2070-4798-2020-15-1-67-75 


\section{INTRODUCTION}

In modern society the problem of students' health is widely discussed. In terms of educational establishments $90 \%$ of those, who enter higher educational establishments have health problems $[7,8]$. Specialists also mention that the level of chronic diseases also increases. The amount of students, who can be included into the main groups for physical culture lessons decreases. Global decrease of functional state and the necessity to change the negative tendency of adaptive potential and physical health level among different groups of population demands great attention from the research workers in the sphere of physical culture and sport $[3,4,5,6,9,10,11]$. In this connection it is important to find the way out, directed toward the conditions creation for innovative methods realization for students' and athletes' health improvement. Students try to master new approaches to their motor activity increase. Nordic walking is the means, which helps to solve the problems of therapeutic, health improving and sports orientation.

Nordic walking very quickly became the part of Russian people life. Politics, directed toward Nordic walking introduction into the life of population, was successful owing to the work fulfilled by the participants of the project and mass media in towns and regions of the Russian Federation. Nordic walking introduction into educational process of students as an effective aerobic exercise helps to realize the idea of Kuper. It says that the effectiveness of each person breathing depends on systematic physical exercises of aerobic orientation. He underlined the role of aerobic exercises in effective breathing formation with sufficient amount of oxygen. It is achieved owing to continuous, moderate and constant physical loads. In this case cardiovascular system development with the help of walking is very important.

Defining students' physical state we take into account the indices, which help to estimate the level of students' physical health.

Important indices, which characterize health state, can be considered morphofucntional indices. It is also important to take into account individual characteristics of students' organism. In order to define the effectiveness of Nordic walking influence it is important to take into consideration adaptive potential of a person [7].

The aim of the research is to study the influence of systematic Nordic walking lessons on students' physical health indices.

\section{MATERIALS AND METHODS}

Before and after the experiment the following indices of students were studied: heart rate (HR), arterial pressure (AP), weight-height index (WHI), vital capacity (VC); life index (LI), Skibinskiy index (SI), physical working capacity according to Ruffier index, adaptive potential (AP) and health level $[1,2]$. The received results handling was held by means of MS Excel. 44 students of the $2^{\text {nd }}$ course State University of Land use Planning and Control took part in the research work. After defining the initial level of the indices we formed one control and one experimental group. In the control group lessons were held taking into account the demands of the physical culture and sport elective course working program. In the experimental group we used the methodology, directed toward Nordic walking use in three directions: therapeutic, health improving and sports. The research was held during the academic year. Taking into consideration the initial level of students' physical health we created the methodology of Nordic walking lessons.

Nordic walking lessons were realized in three interconnected directions. The first directiontherapeutic, was used for students with a low level of physical health (5 students); health-improving- was used for students with the average level of physical health (12 students); sports- was used for students with high level of physical health ( 5 students).

Therapeutic direction of lessons included Nordic walking realization during the experimental period with the duration 10, 20, 25, 30, $90 \mathrm{~min}$; heart load in percentage from maximum - 70, 50, 40, 30\%. Heart rate was defined for one lesson in proportion with the duration of the lesson. For example, 10 minutes lessons, HR-till 140 beats/ min., if the lesson duration is 20 minutes, then HR indices are till 120 beats $/ \mathrm{min}$.

Thus, the duration of the therapeutic orientation lesson is controlled taking into 
account students' HR indices. The main aim of therapeutic orientation Nordic walking realization is cardiorespiratory system effectiveness increase owing to constant physical load increase. The main principle of means realization is gradual and regular character. Methodical recommendation for therapeutic orientation lessons was the rules observation during the speed of movement decrease, duration of the distance increase.

Health-improving orientation realization included the following: generally developing exercises fulfillment for all parts of the body; exercises directed toward physical qualities development:

1) endurance: the average tempo walking in accordance with individual HR indices; a long term walking in a slow tempo or weak intensity;

2) power: exercises with external resistance; exercises with own body weight overcoming; exercises for passive or active muscles tension;

3) quickness: running with maximum possible speed (duration 20-30 seconds); walking with above the average speed. Sports orientation of Nordic walking physical health level (PHL). realization among the students from the experimental group included the following: walking fulfillment according to the following scheme: the first week- 15 minutes with the repetition twice after 10 minutes rest; the $2^{\text {nd }}$ week-20-25 minutes with the repetition 2-4 times after an active rest; the $3^{\text {rd }}$ week - till 30 minutes. During further lessons there was duration of the lessons increase (1 minute). During physical load in a form of Nordic walking students should pay attention to breathing. Forced respiration or dyspnea during walking should be the signal for the tempo of walking decrease.

For all students, independent of the program, which they fulfill, the objective is set in a way that to prevent unpleasant feelings in an organism.

\section{RESULTS AND DISCUSSION}

In order to estimate the level of students physical health from the control and experimental group we used the diagnostics, offered by G.L. Apanasenko (2000).

Picture 1 presents the results of students'

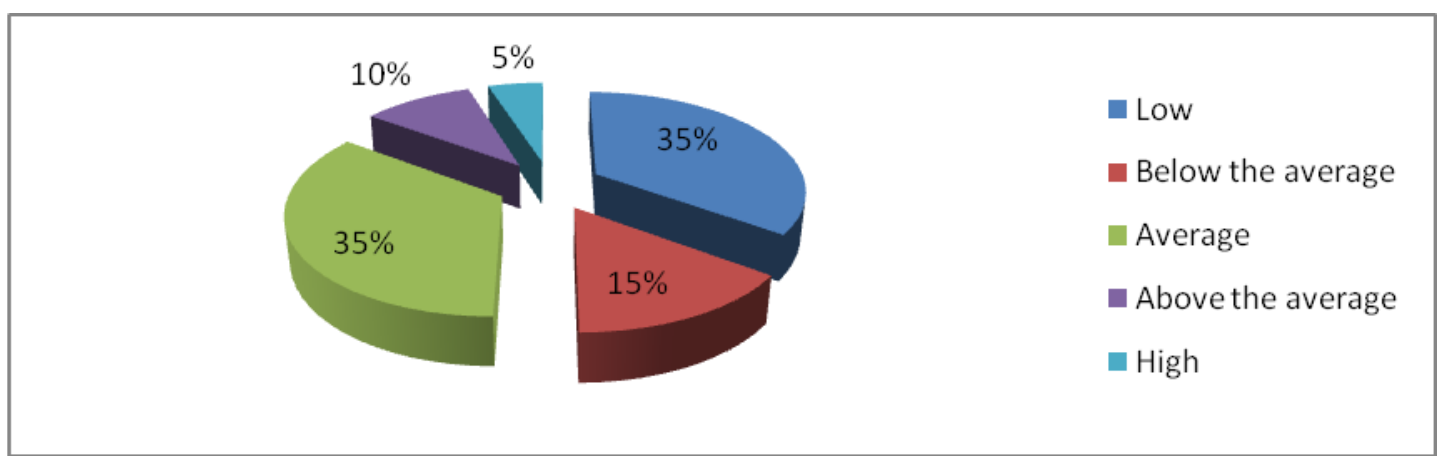

Picture1 - The initial level of physical health in the $2^{\text {nd }}$ course students

Picture 1 shows that $35 \%$ of students have a low level of physical health, $15 \%$ - have below the average level, $45 \%$ - have the average level, $10 \%$ have above the average level and $5 \%$ have a high level of physical health. Low LPH in the $2^{\text {nd }}$ course students is mostly connected with motor activity decrease, especially during examinations.

Table 1 presents the level of physical health in students according to G.L. Apanasenko methodology before the experiment and after their distribution according to the groups. 
Table 1 - The level of physical health in students according to G.L. Apanasenko methodology before the experiment

\begin{tabular}{|c|c|c|c|c|c|c|c|c|c|c|c|}
\hline \multirow[b]{3}{*}{ Group } & \multirow[b]{3}{*}{$\mathrm{n}$} & \multicolumn{10}{|c|}{ Level of physical health among students } \\
\hline & & \multicolumn{2}{|c|}{ Low } & \multicolumn{2}{|c|}{ Below the average } & \multicolumn{2}{|c|}{ Average } & \multicolumn{2}{|c|}{ Above the average } & \multicolumn{2}{|c|}{ High } \\
\hline & & $\begin{array}{l}\text { Number } \\
\text { of people }\end{array}$ & $\begin{array}{l}\text { \% from } \\
\text { general }\end{array}$ & \begin{tabular}{|l|} 
Number \\
of people
\end{tabular} & $\begin{array}{l}\text { \% from } \\
\text { general }\end{array}$ & $\begin{array}{c}\text { Number } \\
\text { of people }\end{array}$ & $\begin{array}{l}\text { \% from } \\
\text { general }\end{array}$ & $\begin{array}{c}\text { Number of } \\
\text { people }\end{array}$ & $\begin{array}{l}\text { \% from } \\
\text { general }\end{array}$ & $\begin{array}{l}\text { Number } \\
\text { of people }\end{array}$ & $\begin{array}{l}\text { \% from } \\
\text { general }\end{array}$ \\
\hline CG & 22 & 8 & 36,4 & 4 & 18,1 & 5 & 22,7 & 3 & 13,6 & 2 & 9,2 \\
\hline EG & 22 & 7 & 31,8 & 4 & 18,1 & 6 & 27,3 & 2 & 9,2 & 3 & 13,6 \\
\hline
\end{tabular}

Table 1 shows that in CG and EG all kinds of in students after the experimental methodology students' physical health level are revealed. realization.

Picture 2 presents physical health level

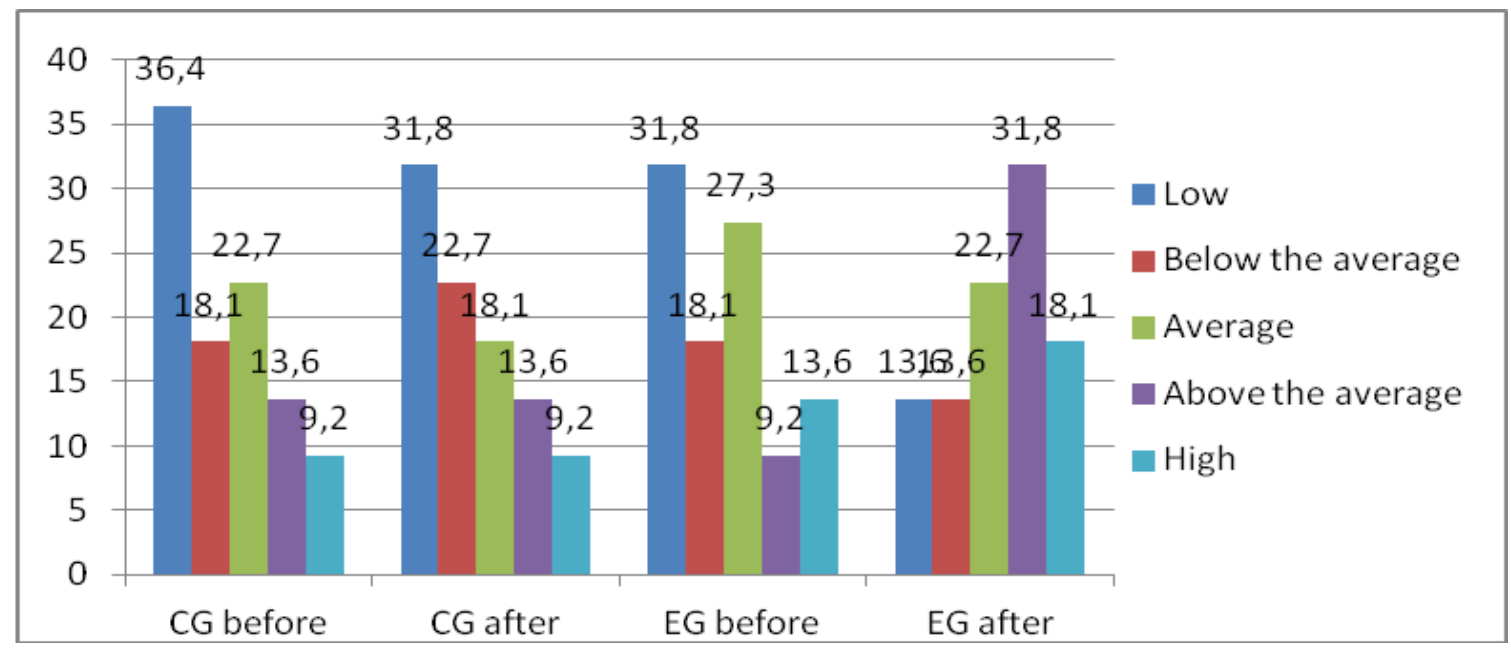

Picture2 - The level of physical health in students after the experiment

Picture 2 shows that students from EG and CG have all levels of physical health. In EG after the methodology realization taking into account three directions (therapeutic, health improving and sports) there was the amount of students increase, who have the average, above the average and high level of physical health. Safe level of students' health is the average and above the average level, where there is no adaptation disorder.

Adaptive potential of students from CG and EG was defined with the help of functional indices study and their transfer into points. According to the received results we estimated the adaptive potential of students as the index of cardiovascular system functional abilities. It characterizes the range between health and illness.

The results of adaptive potential determination in students are presented in table 2.

Table 2 shows that in the studied groups of students there are three variants of adaptive potential of their cardiovascular system demonstration.

Adaptive potential of students from CG and EG before the experiment didn't have validly significant differences. After the experiment the situation with physical health level among experimental group students changed. Before and after the experiment in CG and EG there were no zone of adaptation break-down. Unsatisfactory zone of cardiovascular system adaptation in students from CG and EG we connect with the fact that they didn't have aerobic loads of health-improving, training character for a long time period.

After the experimental methodology realization we received the results. They characterize not only physical health improvement, but also adaptive potential of cardiovascular system improvement to aerobic orientation physical loads. 
Table 2 - Adaptive potential of students according to R.M. Baevskiy methodology

\begin{tabular}{|c|c|c|c|c|c|c|c|c|c|}
\hline \multirow{3}{*}{ Group } & \multirow[b]{3}{*}{$\mathrm{n}$} & \multicolumn{8}{|c|}{ Adaptive potential of cardiovascular system. } \\
\hline & & \multicolumn{2}{|c|}{$\begin{array}{l}\text { Adaptation } \\
\text { disorder }\end{array}$} & \multicolumn{2}{|c|}{ Unsatisfactory } & \multicolumn{2}{|c|}{ Tense } & \multicolumn{2}{|c|}{ Satisfactory } \\
\hline & & $\mathrm{n}$ & $\begin{array}{l}\text { \% from } \\
\text { generaln }\end{array}$ & $\mathrm{n}$ & $\begin{array}{c}\% \text { from } \\
\text { generaln }\end{array}$ & $\mathrm{n}$ & $\begin{array}{l}\text { \% from } \\
\text { generaln }\end{array}$ & $\mathrm{n}$ & $\begin{array}{c}\text { \% from } \\
\text { generaln }\end{array}$ \\
\hline CG & 22 & $\mathrm{O}$ & o & 7 & 31,8 & 4 & 18,1 & 11 & 50 \\
\hline CG after & 22 & $\mathrm{O}$ & o & 8 & 36,6 & 5 & 22,7 & 9 & 40,9 \\
\hline EGbefore & 22 & $\mathrm{O}$ & $\mathrm{O}$ & 7 & 31,8 & 3 & 13,6 & 12 & 54,5 \\
\hline EGafter & 22 & o & $\mathrm{O}$ & $\mathrm{o}$ & o & 1 & 4,5 & 21 & 95,5 \\
\hline
\end{tabular}

It should be noted that the effectiveness criterion of the experimental methodology estimates chosen by us tactics of students' health improvement and training. If we get a positive effect from the achieved level of students' physical health, we can say that the methodology is realized correctly. Individual talks with students after the experiment helped to define the level of changes in a functional state. The main criteria for this are chosen the following: health state in general, health state improvement partially, without changes, only worsening.

The level of physical state in general and its main indices improved in $77,8 \%$ of students. They trained according to the experimental methodology; health state improvement partially was in $20,9 \%$ of students, characterizing changes in cardiovascular, respiratory or muscular systems indices, but at the same time without considerable decrease of other indices; only one student had some indices decrease $(\mathrm{p}<0,05)$.

In the control group during the experiment the level of health decreased in $45,9 \%$ of cases, some morpho-functional indices - in $54,1 \%$ of students $(\mathrm{p}<0,05)$.

The received results help to come to the conclusion, that therapeutic, health-improving and sports effects from Nordic walking methodology in $98,7 \%$ of students from the experimental group was provided owing to an optimal planning of physical loads and their correct realization during the lessons.

PHL indices analysis in students from EG revealed that functional abilities of the organism improved in students, who went in for Nordic walking of therapeutic orientation (59\%), health- improving orientation (27\%) and sports orientation (14\%). In all groups the differences between the initial and final indices of physical health level were valid $(\mathrm{p}<0,05)$.

Thus, cyclic exercises by the example of Nordic walking, directed toward general endurance and aerobic mechanism of muscle activity energy supply development helps not only to increase physical health level, but also the quality of students' life.

Presented by us methodology of Nordic walking lessons with the $2^{\text {nd }}$ course students provides necessary conditions for individual influence lessons organization and help to solve educational, developing and health-improving objectives and achieve the initial aims of its creation and introduction.

All mentioned above helps to create students' profile of physical health for the training effects estimation. Below we present health profile of students from EG before and after the experiment.

Picture 3 presents the example of the physical health level profile creation diagram. It is characterized by gained points.

Picture 3 shows that any diagnostic index can be introduced into the given profile and get an individual profile of physical health of each student. It can make diagnostic indices perception easier.

The main pedagogical conditions of the experimental methodology realization are the following: conditions organization for students' physical health monitoring in a macro cycle of training; a data bank creation of the studied indices; regular analysis of results monitoring; practical recommendations creation. 


\section{Estimation in points}

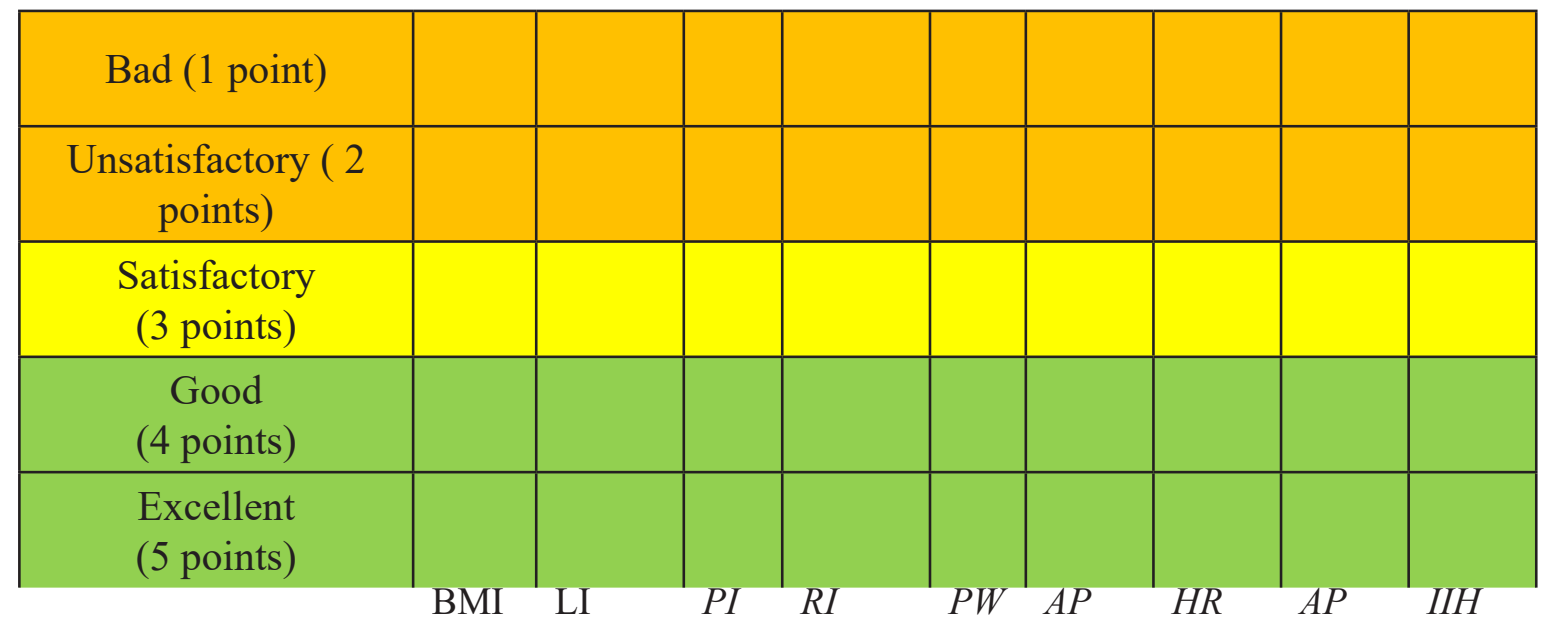

Notes: BMI - body mass index, LI - life index, PI - power index, RI - Robinson index, PW - physical working capacity, AP - adaptive potential, IIH - integral index of health

\section{Pic. 3. Students' health profile creation before and after the experiment}

\section{CONCLUSION}

Thus, functional state indices study in the $2^{\text {nd }}$ course students helped to state that their physical health is at a low level, below the average and the average level. Taking into consideration the studied indices we realized Nordic walking during physical culture lessons in three directions: therapeutic, health improving and sports. The volume of physical load was corrected taking into account an individual level of students' physical health according to the studied indices. In general the methodology realization demands the differentiated approach use to lessons organization, taking into account functional indices. In terms of the students training level increase we see their functional abilities, adaptive potential and an integral health index increase.

\section{REFERENCES}

1. Apnasenko G.L., Popova L.A. Medicinskaya valeologiya [Medical valeology]. Rostov-on-Don: Phoenix. 2000: 248 [In Russ.].

2. Baevskiy R.M., Berseneva A.P. Otsenka adaptacionnyh vozmozhnostej organizma I risk razvitiya zabolevanij [Adaptive abilities of an organism estimation and the risk of diseases development]. Moscow: Medicine. 1997: 23 [In Russ.].

3. Baronenko V.A. Motor activity is the leading universal factor of life optimization and bioprogress (report 1). Valeologiya. 2003; 1: 7-14 [In Russ.].

4. Vanyushin

Yu.S.,

Sitdikov
F.G.Adaptation of cardiac activity among teen-agers to the increasing load. Psihologiya cheloveka. 2001; 27(2): 91-97 [In Russ.].

5. Gizatullina Ch.A., Mutaeva I.Sh. The ways of sprinters' training individualization on the basis of typological characteristics of typological blood circulation. Pedagogiko-psihologicheskie I medico-biologicheskie problemy fizicheskoj kul'tury I sporta. 2012; 3(24): 11-119. URL: http:// kamgifk.ru/magazin/journal.htm [In Russ.].

6. Grankin N.A., Kuznetsova Z.M. Functional state indices and reserve capacities of an organism among cadets-weightlifters. Pedagogikopsihologicheskie I medico-biologicheskie problemy fizicheskoj kul'tury I sporta = Pedagogicalpsychological and medical-biological problems of physical culture and sport. 2017; 12(3): 58-67. DOI: 10.14526/03_2017_232

7. Kozhevnikova N.G. The role of risk factors of the way of life in students' sickness rate formation. Zemskij doktor. 2011; 6: 13-17 [In Russ.].

8. Sharifullina S.R., Martynova V.A., Askhamova A.A., Zhestkova Yu.K. Differentiated approach to physical upbringing organization among the future teachers on the basis of morphofunctional indices. Teoriay I praktika fizicheskoj kul'tury I sport = Theory and practice of physical culture. 2017; 8: 18-20 [In Russ., In Engl.].

9. Petrov R.E., Mutaeva I.Sh., Ionov A.A. Aerobic threshold and potentialities of cardiovascular system determination and estimation among skiers-racers (male) on the basis of gradually increasing bicycle ergometric load use. Pedagogikopsihologicheskie I medico-biologicheskie problemy fizicheskoj kul'tury I sporta = The Russian Journal of Physical Education and Sport. 2018; 13(2): 
198-206. URL: http://journalsport.ru/index. $\mathrm{php} / \mathrm{en} /$ archive/106-uncategorised/14-3/106tom-13-2-2018 [In Russ., In Engl.].

10. Morso L., Hartvigsen J., Puggaard L., Manniche C. Nordic walking and chronic low back pain: Design of a randomized clinical trial. $B M C$ Musculoskeletal Disorders. 2006; 7: 77.
11. Schiffer T., Knicker A., Hoffman U., Harwig B., Hollmann W.Struder H.K. Physiological responses to Nordic walking, walking and jogging. European Journal of Applied Physiology. 2006; 98: 56-61.

Submitted: 29.12.2019

Author's information:

Svetlana V. Nageykina - Lecturer, Associate Professor, State University of Land use Planning and Control, 105064, Russia, Moscow, Kazakova str., House 15, e-mail: sveti-200o@yandex.ru 